\title{
A MALETA DE BRUCE CHATWIN, CIFRA DA HISTÓRIA
}

\author{
Kelvin Falcão Klein \\ Universidade Federal de Santa Catarina
}

Resumo: O ensaio procura investigar a repercussão crítica possível de uma cena da infância do escritor Bruce Chatwin, vivida durante a Segunda Guerra Mundial, da qual surgem dois artefatos de ampla significação histórica: a maleta e a máscara de gás. A máscara de gás, no entanto, guarda a peculiaridade de ser destinada às crianças e, por isso, ter o formato e as feições do personagem Mickey Mouse. Tanto a maleta quanto a máscara são resgatadas a partir da noção de "imagem dialética", tal como desenvolvida por Walter Benjamin. O ensaio também se vale das reflexões deste autor sobre o personagem Mickey Mouse, ampliando a reflexão também em direção às reflexões de Giorgio Agamben sobre a miniaturização como cifra da história, fenômeno que se observa nos dois artefatos selecionados para análise no ensaio, a maleta e a máscara de gás. $\mathrm{O}$ texto indica e se alinha àquilo que se configura como uma nova sensibilidade historiográfica nas ciências humanas, baseada na leitura dos rastros deixados pelos objetos e por suas singularidades morfológicas.

Palavras-chave: Imagem dialética. Segunda Guerra Mundial. Bruce Chatwin. Miniaturização. Memória.

Tudo começa durante a II Guerra Mundial, com uma máscara de gás dentro de uma maleta, um artigo de sobrevivência para o caso de emergência. A máscara pertence a uma criança e, por conta disso, tem um formato e uma configuração muito peculiares: trata-se de uma máscara com as feições do Mickey Mouse, fabricada com o intuito de tornar menos traumático o contato das crianças com o cotidiano da guerra. A máscara está numa maleta porque viaja com uma família reduzida, mãe e filho, que trocam de endereço com frequência, fugindo dos bombardeios enquanto aguardam notícias do pai, capitão da Marinha Real Britânica. A criança em questão é Bruce Chatwin, o escritor nascido em 1940 e morto em 1989, autor de livros que misturam ensaio, ficção e relato de viagem, como Na Patagônia, $O$ rastro dos cantos e Utz. Sua experiência durante a guerra, que coincidiu com suas primeiras impressões sobre o mundo, repercutiu ao longo de sua trajetória como narrador, sobretudo no

Esta obra está licenciada sob uma Licença Creative Commons.

\footnotetext{
* Doutor em Teoria Literária pela Universidade Federal de Santa Catarina (UFSC) e Mestre em Literatura Comparada pela Universidade Federal do Rio Grande do Sul (UFRGS). Autor de Conversas apócrifas com Enrique Vila-Matas (Ed. Modelo de Nuvem, 2011). Contato: kelvin.klein@gmail.com
}

Anu. Lit., Florianópolis, v. 19, n. 1, p. 121-133, 2014. ISSNe 2175-7917 
que diz respeito às suas ideias sobre o nomadismo, a deambulação e a fragilidade dos territórios e das fronteiras.

Quem conta a história é Nicholas Shakespeare, biógrafo de Chatwin. "Home was a suitcase", escreve Shakespeare, "a roll-up canvas holdall, with bags at both ends, and a solid black Revelation trunk known as the Rev-Robe. The trunk opened up like a wardrobe and Bruce had use of two of the drawers - for his clothes and his Mickey Mouse gas mask". Shakespeare cita também algumas anotações de Chatwin, presentes em seus cadernos inéditos preservados na Biblioteca Bodleiana de Oxford, anotações sobre sua vivência de infância durante a guerra: "I knew that once the bombs began to fall, I could curl up inside the RevRobe and be safe", escreve Chatwin, citado por Shakespeare. E Chatwin finaliza suas reminiscências escrevendo que o período foi "quite definitely a scar", um comentário, segundo Shakespeare, "about the effect of those homeless years" (SHAKESPEARE, 2000, p. 24). O que primeiro chama a atenção é que a maleta, compartilhada por mãe e filho (Bruce tinha direito a duas divisórias), era um signo tanto da ausência de casa quanto da possibilidade, mesmo que remota e dificultosa, de ter uma casa (Bruce sabia que, no caso de bombardeio, ele podia entrar na maleta e sentir-se a salvo). Tanto a maleta quanto a máscara de gás do Mickey Mouse são imagens complexas, indicam conforto e terror, segurança e instabilidade, simultaneamente ${ }^{1}$.

As máscaras de gás com as feições de Mickey Mouse começaram a ser produzidas a partir de 1942, nos Estados Unidos. O medo de que a guerra pudesse chegar ao território do país foi intensificado com o ataque japonês a Pearl Harbor, em dezembro de 1941. Diante disso, iniciou-se a fabricação intensa de máscaras para não-combatentes, para distribuição entre os civis. Uma das empresas responsáveis pela fabricação das máscaras, a Sun Rubber Company, teve a ideia de não apenas fabricar modelos menores para as crianças, mas de produzi-los de forma mais atraente. O contato com Walt Disney, criador do personagem e

\footnotetext{
${ }^{1}$ A presença da máscara de gás no imaginário de Bruce Chatwin pode ser rastreada até Colina negra, um romance publicado em 1982 (sua única publicação realizada em moldes narrativos tradicionais, ou seja, sem intervenção ensaística ou de relato de viagens, como é costumeiro em seus outros livros). É importante também frisar que a aparição da máscara de gás se dá também por meio de uma imagem, uma fotografia que cristaliza o momento. O narrador está contando a história de Jim, arreeiro do Regimento Fronteiriço de Gales Sul durante a I Guerra Mundial, responsável pelo cuidado com as mulas. "O que mais o enfurecia era ver as mulas morrerem pela ação do gás. Ele sobreviveu a um ataque com gás, ao passo que toda a sua tropa de mulas morreu - e isso o deixou furioso. Marchou em direção ao tenente, saudou-o rispidamente e falou sem pensar duas vezes: 'Se posso ter uma máscara contra gás, por que minhas mulas não podem?'. Aquela lógica causou tal impressão ao tenente que ele mandou um relatório ao general. Este, ao invés de ignorá-lo, respondeu com uma nota de felicitações. Em 1918, a maioria das unidades britânicas equipou seus cavalos e mulas com máscaras contra gás, ao passo que os alemães continuavam perdendo suas montarias", e, ao contar a história aos amigos, Jim "tirava do bolso a carta do general ou a foto dele próprio acompanhado de duas mulas - os três com máscaras contra gás" (CHATWIN, 2005, p. 174).
} 
detentor dos direitos de imagem e licenciamento, ocorreu em seguida e, diante de sua aprovação, a Sun Rubber Company passou à fase de testes, criando protótipos para a máscara. Foram produzidos aproximadamente mil exemplares da máscara de gás com as feições de Mickey Mouse pela Sun Rubber Company, mas um número muito maior de máscaras mais simples foi distribuído - geralmente com uma ilustração do Mickey colada ao tambor frontal de filtragem e com pedaços redondos de borracha no alto, fazendo as vezes de orelhas. O que cruzou o oceano, portanto, não foram as máscaras tal como produzidas (ou idealizadas) pela Sun Rubber Company em conjunto com Walt Disney, mas a simples "ideia”, "fantasia" ou "ficção" de uma máscara do Mickey Mouse, que era improvisada com adesivos, pedaços de borracha e intervenções na coloração.

Em suas memórias da infância passada durante a II Guerra Mundial, intituladas An Evacuee's Story: a North Yorkshire Family in Wartime, John T. Wright escreve que por volta de 1942, "we were told by Miss Thorne that, if the Germans came, they might use 'nasty smells to make us feel ill' and we had to practice putting on our newly issued Mickey Mouse gas masks". Em seguida, Wright descreve a máscara: "they had a bright red, rubber bit at the front and the circular eyepieces had blue rims but some of the children were frightened of them and hated the choking, claustrophobic feeling and the rubbery smell" (WRIGHT, 2007, p. 84). Pat Williams e James Denney, na biografia que publicaram de Walt Disney, escrevem que a máscara britânica era de fato diversa daquela norte-americana: "during the London blitz, English children were issued gas masks with pictures of Mickey on them”, ou seja, o expediente não da confecção de detalhes em borracha, mas o simples acréscimo de adesivos com a imagem de Mickey Mouse (WILLIAMS; DENNEY, 2004, p. 60). Kirstin Olsen, por outro lado, em seu guia de leitura para o romance $O$ senhor das moscas, de William Golding, ao comentar a importância da experiência da guerra para a realização do livro, escreve que já no início da guerra "44,000,000 gas marks were issued, with a special style called the 'Mickey Mouse' mask made in bright colors for toddlers", lembrando que "toddlers" são crianças de um a três anos de idade (OLSEN, 2000, p. 171).

Independente da configuração específica de cada tipo de máscara, o que permanece como traço comum é a tentativa de resgatar uma imagem familiar, Mickey Mouse, e mesclála a uma imagem nova e de natureza completamente diversa, até contraditória, que é a imagem da guerra e do conflito, especialmente dos hipotéticos ataques com gás aos civis (algo que não se concretizou durante a guerra). Não se sabe com certeza de onde partiu a ideia de ligar a imagem de Mickey Mouse à fabricação das máscaras, pois existem indícios de que tal 
prática já estava em desenvolvimento na Inglaterra no início da guerra, bem antes, portanto, do ataque a Pearl Harbor. O que é certo é a presença imediatamente reconhecível da imagem de Mickey Mouse, e sua igualmente imediata associação com o universo infantil, o que indica também a eficácia da incipiente "sociedade do espetáculo" que então se armava. A imagem reconhecível de Mickey Mouse diz respeito também a esse projeto de difusão massiva da informação, típica da década de 1930 e seu fascínio pelo cinema, por exemplo. Não é por acaso, portanto, que Walter Benjamin tenha escolhido Mickey Mouse como exemplo para suas discussões sobre a reprodutibilidade técnica e sobre as possibilidades de uso político da imagem e do cinema. "O cinema introduziu uma brecha na velha verdade de Heráclito segundo a qual o mundo dos homens acordados é comum, o dos que dormem é privado", escreve Benjamin, “e o fez menos pela descrição do mundo onírico que pela criação de personagens do sonho coletivo, como o camondongo Mickey, que hoje percorre o mundo inteiro" (BENJAMIN, 1994, p. 190).

A imagem de Mickey Mouse pode passar tranquilidade às crianças durante a guerra porque é familiar, porque permite a distração da criança do mundo real em direção a um mundo onírico, alternativo e paralelo. Em 1931, Walter Benjamin escreveu uma nota breve sobre Mickey Mouse, que permaneceu inédita até a publicação de suas obras completas na década de 1970. Nessa nota, Benjamin comenta a aproximação possível das histórias de Mickey Mouse com o universo dos contos de fadas, e como em ambos há uma evocação "não-simbólica", no sentido de que Mickey Mouse deve ser pensado como uma entidade em si mesmo, e não como símbolo de alguma outra coisa, ou de uma condição humana ainda a ser revelada. "Todos os filmes de Mickey Mouse estão baseados no motivo da fuga de casa com o objetivo de aprender o que é o medo", escreve Benjamin, e completa: a popularidade desses filmes reside no fato "de que o público reconhece neles sua própria vida" (BENJAMIN, 1999, p. 545).

Os detalhes da mescla entre Mickey Mouse e a guerra ficam pouco a pouco mais visíveis, sobretudo a partir do momento em que Benjamin chama a atenção para esse elemento temático recorrente nos desenhos do "camondongo", ou seja, a fuga de casa com o objetivo de aprender o que é o medo. As aventuras de Mickey Mouse foram marcadas, desde o início, por esse elemento de arrojo e destemor, e a aproximação de sua imagem com o instrumento da máscara de gás pode servir não apenas para o conforto das crianças, mas também para uma espécie de personificação do desenho por parte das crianças. Ou seja, o atravessamento entre o personagem de desenho e a utilidade da máscara de gás serve tanto 
para acalmar as crianças em um momento de tensão e emergência - com o procedimento de incorporar a uma situação extrema um elemento lúdico, do universo infantil - quanto para imbuí-las de um sentimento de coragem, que é precisamento um dos traços de caráter mais marcantes de Mickey Mouse. Diante disso, forma-se um curioso circuito de personificações, já que o primeiro movimento cognitivo no contato com Mickey Mouse diz respeito a sua capacidade de fala e de articulação, elementos que o aproximam indiscutivelmente do ser humano. Mas a personificação volta ao ponto de origem no momento em que a criança, durante a guerra, é estimulada a apreender, através da máscara, certas características de Mickey Mouse para sobreviver. Daí a ênfase de Benjamin no caráter onírico do personagem, que se move e fala como um ser humano sem deixar de ser um rato - as duas condições existem simultaneamente, assim como no caso da máscara de gás o conforto da imagem infantil do camondongo existe simultaneamente com a ameaça de ataque e morte, representada pela própria materialidade do objeto, a máscara ${ }^{2}$.

No momento em que abandona a tela do cinema ou a página da revista e atinge sua simbiose com a máscara de gás, a imagem de Mickey Mouse ganha uma materialidade inesperada, o que redunda também em uma mescla entre o onírico e o mundo real. A partir do momento em que se transforma em máscara de gás, a imagem de Mickey Mouse passa a operar em um registro duplo e contraditório, pertencendo tanto ao registro onírico da representação gráfica da fantasia quanto ao registro prático da sobrevivência em tempos de guerra. E é precisamente o contexto histórico que dá a medida da importância desse atravessamento, uma vez que os dois registros eram fundamentais para a manutenção da vida e não podiam ser articulados separadamente. Se o registro onírico prevalecesse, a criança não teria a dimensão precisa da importância da máscara e sua utilidade em caso de ataque; se o registro prático prevalecesse, a criança corria o risco de se entregar ao pânico e não realizar os procedimentos necessários para o uso da máscara. Por isso a imagem inicial da infância de Bruce Chatwin é tão importante, porque, além de trazer à tona esse objeto tão peculiar - a máscara de gás do tipo Mickey Mouse -, também faz a ligação entre a necessidade de

\footnotetext{
${ }^{2}$ Ainda resta por investigar as relações possíveis entre as reflexões de Benjamin sobre Mickey Mouse e aquelas sobre o escritor Franz Kafka. Tanto em Kafka quanto em Mickey Mouse, Benjamin rastreia uma mescla complexa entre o onírico e o factual, uma mescla das referências realistas e prosaicas com uma dimensão quase delirante no que diz respeito ao atravessamento ontológico entre homem e animal. É preciso relembrar que Kafka escreveu um conto sobre esse atravessamento que envolvia ratos como personagens, "Josefina, a cantora ou O povo dos camundongos" (ver KAFKA, 1998, p. 37-59), conto apropriado e reformulado por Roberto Bolaño em "El policía de las ratas" (ver BOLAÑO, 2003, p. 53-86). O atravessamento ontológico entre homem e animal, especialmente nessa configuração imagética da máscara, ou seja, a configuração da metamorfose do rosto e da troca de cabeças, era uma das preocupações centrais da discussão estética do entreguerras - basta pensar, por exemplo, no caso do grupo Acéphale de Georges Bataille. Investiguei em parte essa questão no artigo "Metamorfoses nas vanguardas: entre o homem e o animal" (ver KLEIN, 2010, p. 1-15).
} 
manutenção de um mundo onírico e a preocupação com a sobrevivência, que acarreta um estado de permanente atenção e mobilidade. No caso de Chatwin, a maleta era tanto a casa quanto a ausência de casa; e dentro dela estava a máscara, que era tanto imagem do conforto e de familiaridade quanto indício permanente de que algo ruim poderia acontecer, sem aviso.

Tal situação torna-se produtiva em termos de análise crítica e cultural por uma série de motivos. Em primeiro lugar, tem-se acesso a um contexto histórico bastante complexo que é, até certo ponto, codificado na materialidade de objetos bem específicos: uma maleta, uma máscara de gás. Em segundo lugar, os objetos transcendem suas características imediatas e ganham também uma representatividade estética e filosófica, porque são lidos e observados como elementos visíveis de um conjunto de experiências dificilmente quantificáveis ou mesmo apreensíveis (o medo, o terror, a esperança, a infância, a memória). Como é impossível ter acesso direto ao medo, ao terror ou à memória de infância, tanto a maleta quanto a máscara de gás funcionam como dispositivos de personificação desses elementos - e são esses objetos que permitem o acesso a esse espaço de tempo e espaço que é possível situar historicamente, e que diz respeito à II Guerra Mundial de forma geral e às memórias de um escritor como Bruce Chatwin em particular, bem como às reflexões de Walter Benjamin.

A maleta e a máscara de gás, como imagens representativas de uma série de elementos contraditórios mas interligados e interdependentes, podem ser classificadas a partir da categoria benjaminiana de "imagem dialética". "O índice histórico das imagens diz", escreve Benjamin na obra das Passagens, "não apenas que elas pertencem a uma determinada época, mas, sobretudo, que elas só se tornam legíveis numa determinada época"; atingir essa legibilidade, continua Benjamin, "constitui um determinado ponto crítico específico do movimento em seu interior. Todo o presente é determinado por aquelas imagens que lhe são sincrônicas: cada agora é o agora de uma determinada cognoscibilidade. Nele, a verdade está carregada de tempo até o ponto de explodir". No entanto, "não é que o passado lança sua luz sobre o presente ou que o presente lança luz sobre o passado", mas "a imagem é aquilo em que o ocorrido encontra o agora num lampejo, formando uma constelação". Ou, em outras palavras: "a imagem é a dialética na imobilidade". E Benjamin finaliza afirmando que “enquanto a relação do presente com o passado é puramente temporal, a do ocorrido com o agora é dialética - não de natureza temporal, mas imagética. Somente as imagens dialéticas são autenticamente históricas", isto é, “imagens não arcaicas", pois "a imagem no agora da cognoscibilidade carrega no mais alto grau a marca do momento crítico, perigoso, subjacente a toda leitura" (BENJAMIN, 2006, p. 505 [N 3, 1]). 
A maleta e a máscara de gás, no entanto, são tanto imagens quanto objetos, remetem tanto a uma legibilidade de ordem filosófica ou estética (como aquela que está em operação na definição de Benjamin de que "a imagem é a dialética na imobilidade") quanto a uma legibilidade de ordem histórica (como aquela revelada na aproximação de Benjamin entre o "agora da cognoscibilidade" e o "momento perigoso" da leitura). A leitura dessa cena complexa na biografia de Bruce Chatwin - uma cena que, como vimos, foi compartilhada por milhares de crianças tanto nos Estados Unidos quanto na Grã-Bretanha -, a cena da emergência da maleta e da máscara de gás, permite também a produtiva conjunção de dois campos de reflexão de Walter Benjamin: em primeiro lugar, a consideração teórica e filosófica do estatuto da imagem dentro de um contexto histórico conturbado; em segundo lugar, o espaço dado em sociedade aos objetos, tanto aqueles que ainda possuem serventia quanto aqueles já obsoletos, ou que pertencem a épocas passadas. Dentro dessa última categoria, os brinquedos sem dúvida ocuparam um lugar de destaque nos escritos e na vida de Benjamin, que era um colecionador desse tipo de artefato (prática atestada por textos tão diversos como "Velhos brinquedos" e "História cultural do brinquedo", ambos de 1928, e "Brinquedos russos" e "Elogio da boneca", ambos de 1930).

A máscara de gás de Mickey Mouse, a partir desse contexto, surge como um artefato complexo, que condensa em si uma série de derivas contraditórias. É precisamente essa tensão interna do objeto que marca seu "agora da cognoscibilidade", porque é essa tensão que impede a completa cooptação do objeto por parte de qualquer uma das derivas que o solicitam. A máscara de gás de Mickey Mouse é tanto um brinquedo, por conta de ser destinada às crianças e solicitar o manuseio (era preciso testá-la e praticar seu uso, como atestam as memórias de John T. Wright), quanto uma imagem intangível, que remete ao espetáculo, à atmosfera cinematográfica e aos atributos do personagem. Mas é também um artefato de guerra, um instrumento de defesa, um artefato que faz parte de uma série de esforços orquestrados que tem como objetivo a manutenção de um território e a vitória sobre um inimigo. É impossível determinar com certeza onde começa a máscara e onde termina a imagem do personagem de desenho, ou ainda, onde começa o brinquedo e onde termina a ferramenta de guerra - ou, em outra ordem de reflexão, onde começa a concentração utilitária da sobrevivência e onde termina a fantasia infantil de personificação.

Existe um ponto de intersecção que leva da imagem ao objeto, do espetáculo da tela do cinema à materialidade do evento, e, no caso específico da máscara de gás de Mickey Mouse, um ponto de intersecção que leva da infância à guerra, do brinquedo ao artefato de 
guerra. Em ensaio intitulado "O país dos brinquedos: reflexões sobre a história e sobre o jogo", calcado em Benjamin mas sobretudo em Claude Lévi-Strauss, Giorgio Agamben escreve que a "essência do brinquedo" é "algo de eminentemente histórico: aliás, por assim dizer, é o Histórico em estado puro", pois, "em nenhum lugar como em um brinquedo, poderemos captar a temporalidade da história no seu puro valor diferencial e qualitativo", ou seja, "não em um monumento, que conserva no tempo o seu caráter prático e documental", e também "não em um objeto de antiquário, cujo valor é função de uma antiguidade quantitativa", e "não em um documento de arquivo, que extrai seu valor do fato de ser inserido, em uma cronologia, em uma relação de contiguidade e de legalidade com o evento passado", no que se refere a todos estes objetos, continua Agamben, "o brinquedo representa algo a mais, algo de diverso", pois "o brinquedo, desmembrando e distorcendo o passado ou miniaturizando o presente - jogando, pois, tanto com a diacronia quanto com a sincronia presentifica e torna tangível a temporalidade humana em si” (AGAMBEN, 2005, p. 86-87).

Mas essas considerações só abarcam uma parte daquilo que surge a partir da observação da máscara de gás do tipo Mickey Mouse, um artefato que permanece obscuro historicamente por conta de sua aparente banalidade ou trivialidade. Contudo, é nessa aparência de trivialidade que se esconde a potencialidade do artefato, sua capacidade de simultaneamente revelar e camuflar sua múltipla inserção histórica. No caso da máscara de gás de Mickey Mouse, essa natureza múltipla, como visto anteriormente, é inerente a sua configuração como objeto fabricado, cujo propósito básico é o de mesclar proteção e atenção, consciência de que há uma guerra em andamento e oportunidade de desvio cognitivo dessa condição histórica traumática. A partir dessa perspectiva, a máscara de gás de Mickey Mouse, partindo de sua condição de "imagem dialética", agrega também uma dimensão de brinquedo, uma dimensão, no entanto, que é complexificada em duas dimensões: em primeiro lugar, remete ao presente imediato da imagem de Mickey Mouse, um personagem do imaginário infantil que diz respeito a um contexto muito preciso, de fortalecimento da linguagem midiática e espetacularizada então incipiente; em segundo lugar, a máscara de gás de Mickey Mouse movimenta também uma série de procedimentos de intervenção no tempo, algo que fica evidente nas considerações de Agamben sobre a articulação entre diacronia e sincronia própria do contexto imaginativo que surge quando da manipulação dos artefatos pelas crianças.

O paulatino descortinamento dessa multiplicidade de elementos só é possível, não somente no caso da máscara de gás de Mickey Mouse, mas em muitos outros artefatos, a 
partir de uma mudança na sensibilidade historiográfica, uma mudança em direção a uma percepção das singularidades que configuram cada objeto. O trabalho de reflexão sobre a história transfigura-se em trabalho detetivesco, de investigação de pistas, rastros e tênues vestígios deixados pelo tempo nos objetos e pelos objetos no tempo. Essa nova sensibilidade marca todo o exercício de Benjamin no livro das Passagens, por exemplo, e em outro trabalho de fôlego contemporâneo, o Atlas Mnemosyne, de Aby Warburg (sobre a articulação entre os dois projetos, ver KLEIN, 2013, p. 15-25). Giorgio Agamben seguiu e aprimorou essa sensibilidade em muitos trabalhos, tais como Signatura Rerum (AGAMBEN, 2008) ou Ninfe (AGAMBEN, 2007), no que foi acompanhado por outros pensadores italianos, como Carlo Ginzburg, especialmente no seminal ensaio "Sinais: raízes de um paradigma indiciário" (GINZBURG, 1990, p. 143-179), e Maurizio Ferraris, em Documentalità (2009). Em outras latitudes, e dentro da vastíssima produção nesse campo de pesquisa, é possível citar Traces remain, de Charles Nicholl (2011), The Geography of Imagination, de Guy Davenport (1997), e Descartes Bones, de Russell Shorto (2008). Todos esses trabalhos compartilham um olhar para o detalhe revelador, para a minúcia do artefato que, uma vez removida de sua aparente trivialidade, oferece novas perspectivas de análise ${ }^{3}$.

A obra de Bruce Chatwin também se encaixa nessa nova sensibilidade. Seu livro $O$ rastro dos cantos, publicado originalmente em 1986, evoca parcelas substanciais de trabalhos como os de Ginzburg ou Ferraris, preocupados em pensar certas configurações históricas do presente estabelecendo pontos de fuga arcaicos e de longa duração (Ginzburg, no ensaio citado, tece especulações até o homem das cavernas; e Ferraris, por sua vez, aos gregos, entre outras civilizações antigas). $O$ rastro dos cantos, de Chatwin, é uma investigação sobre as rotas nômades da Austrália, chamadas justamente de "rastro dos cantos", uma intrincada rede de referências geográficas, melódicas, históricas e imagéticas compartilhadas pelos nativos há milhares de anos. Em paralelo à investigação etnográfica que leva a cabo, Chatwin também incorpora ao livro uma série de citações e anotações que dizem respeito àquilo que ele qualifica como uma predisposição inata da humanidade em direção ao nomadismo. $\mathrm{Na}$ percepção de Chatwin, amparada por uma série de trechos de obras de várias temporalidades e

\footnotetext{
${ }^{3}$ Um trabalho que contribuiu muito para o amadurecimento do tipo de leitura que realizo neste ensaio foi $O$ casaco de Marx: roupas, memória, dor, de Peter Stallybrass, no qual o autor analisa o contexto histórico de escrita de $O$ Capital a partir da investigação de um detalhe aparentemente trivial, o casaco de Karl Marx. Com recursos financeiros limitados e uma numerosa família para sustentar, Marx tinha necessidade de, eventualmente, penhorar seus objetos, entre eles seu casaco de inverno. Era esse casaco, no entanto, que lhe permitia manter as aparências necessárias para frequentar a sala de leitura do Museu Britânico, local no qual realizava as pesquisas para a escrita de sua obra. Nas palavras de Stallybrass: "O casaco de inverno de Marx estava destinado a entrar e a sair da loja de penhores durante todos os anos 1850 e o início dos anos 1860. E seu casaco determinava diretamente que trabalho ele podia fazer ou não" (STALLYBRASS, 2008, p. 48).
} 
tradições, a moradia, a casa e o pertencimento são categorias em permanente problematização dentro do escopo da experiência humana no mundo. Chatwin intitula essa coleção de trechos de "Dos cadernos de anotações" (CHATWIN, 1996, p. 226-281).

Não é possível determinar até que ponto a experiência de infância de Chatwin durante a II Guerra Mundial repercute na eleição dos temas e procedimentos de sua obra literária, embora seja possível, sim, notar e explorar a analogia existente entre a experiência do passado (definida por Chatwin, como visto no trecho citado de sua biografia, como uma "cicatriz") e as premissas que guiam suas reflexões sobre o nomadismo. A infância durante a guerra mostrou, não somente a Chatwin, mas também a John T. Wright e tantos outros, que a casa, a moradia e o pertencimento são categorias passíveis de modificação abrupta e inesperada - conforme as palavras de Nicholas Shakespeare, "casa era uma maleta" para Chatwin. E, no interior dessa casa, repercutindo também a oscilação do pertencimento, estava a máscara de gás de Mickey Mouse. Os dois objetos, maleta e máscara, operavam em duplos registros, simultâneos e contraditórios, afirmando e negando a possibilidade de conforto e pertencimento. Esse dilema, no entanto, não era um capricho ou um excentricidade, e sim uma estratégia de sobrevivência repetida em larga escala na vida de milhões de famílias.

A maleta que guarda a máscara é uma miniatura da casa, da moradia e do pertencimento. Uma miniaturização, no sentido que Agamben dá a esse termo no ensaio citado acima, da experiência de não ter lugar típica da guerra ${ }^{4}$. Por isso que Agamben (2005, p. 88) afirma que a miniaturização é "a cifra da história", porque ao mesmo tempo em que dá acesso ao evento traumático que lhe permitiu a emergência (a maleta como casa por conta da guerra), camufla esse acesso a partir de sua singularidade enquanto objeto (pois a maleta, ao mesmo tempo em que é miniaturização da moradia, é também ausência de moradia, e esse conflito está posto na própria materialidade do objeto). Na dinâmica da vida e da escrita de Bruce Chatwin, por exemplo, a maleta não pode ser apreendida somente a partir daquilo que significa diretamente, ou seja, a partir de sua dimensão utilitária, ainda que essa dimensão seja imprescindível para a compreensão mais básica do contexto - pois não há dúvida de que a maleta servia para carregar as posses da família, além das roupas e da máscara de gás de

\footnotetext{
${ }^{4} \mathrm{O}$ tema da miniaturização como consequência da contingência traumática da guerra é bastante amplo e complexo, e tenho me dedicado a ele há bastante tempo, especialmente em seu aproveitamento por Marcel Duchamp no desenvolvimento das "caixas-maleta" (boîte-en-valise) e também pelo escritor Enrique Vila-Matas em seu livro História abreviada da literatura portátil. Em linhas gerais, a maleta e a miniaturização representam respostas tanto de ordem estética quanto experimental ao ambiente histórico hostil não apenas da guerra, mas também do cotidiano em estados totalitários. A presente investigação em torno da máscara de gás de Mickey Mouse e a presença da maleta como substituto da casa para Bruce Chatwin representa uma sorte de continuidade de outros trabalhos que publiquei, tais como "Elogio da portabilidade" (KLEIN, 2009, p. 135-154) e "Enrique Vila-Matas em cinco imagens" (KLEIN, 2009a, p. 88-101).
} 
Mickey Mouse de Bruce Chatwin. Essa dimensão utilitária, no entanto, é atravessada pela dimensão da "cicatriz", ou seja, pela dimensão imaginativa ou efetivamente ficcional que se encarrega da sobrevivência da imagem da maleta como imagem da instabilidade e da exceção em tempos de guerra. Todo esse cenário complexo de atravessamentos sobrevive na imagem da máscara de gás de Mickey Mouse, testemunha permanente, em sua materialidade, da indissociabilidade de contrários inerente ao objeto na modernidade.

"O brinquedo infantil não atesta a existência de uma vida autônoma e segregada", escreve Benjamin em 1928, no ensaio "História cultural do brinquedo", e continua: "mas é um diálogo mudo, baseado em signos, entre a criança e o povo" (BENJAMIN, 1994, p. 248). O brinquedo surge como o espaço de um diálogo que ocorre entre a criança e a comunidade da qual faz parte, um diálogo baseado em signos (ou em "cifras", segundo a nomenclatura de Giorgio Agamben), signos e cifras que devem ser decifrados no trabalho de leitura dos artefatos do passado. A experiência muito particular da criança no contato com seus brinquedos é, durante a guerra, transfigurada em uma experiência complexa, que mescla tanto elementos de familiaridade e conforto quanto de violência e trauma - tal experiência complexa é impressa em uma vasta gama de objetos, dentre os quais a máscara de gás de Mickey Mouse, conforme elaborado ao longo deste ensaio. O trabalho de deciframento das cifras e signos dos objetos é interminável, especialmente se tais objetos são percebidos a partir de uma desconstrução da pretensa trivialidade, armando as bases de um paradigma de análise baseado nos rastros e nos detalhes.

\section{Referências}

AGAMBEN, Giorgio. Signatura Rerum. Sul metodo. Turim: Bollati Boringhieri, 2008. Ninfe. Turim: Bollati Boringhieri, 2007.

O país dos brinquedos: reflexões sobre a história e sobre o jogo. In: Infância e história. Destruição da experiência e origem da história. Trad. de Henrique Burigo. Belo Horizonte: Editora da UFMG, 2005, p. 79-107.

BENJAMIN, Walter. Passagens. Trad. Irene Aron et al. (Org. Willi Bolle). Belo Horizonte/São Paulo: Editora da UFMG/Imprensa Oficial do Estado de São Paulo, 2006.

Press, 1999.

Mickey Mouse. In: Selected Writings. Volume 2, 1927-1934. Cambridge: Harvard

A obra de arte na era de sua reprodutibilidade técnica. In: Obras escolhidas: magia e técnica, arte e política. Trad. de Sérgio Paulo Rouanet. São Paulo: Brasiliense, 1994. 
História cultural do brinquedo. In: Obras escolhidas: magia e técnica, arte e política. Trad. de Sérgio Paulo Rouanet. São Paulo: Brasiliense, 1994.

BOLAÑO, Roberto. El policía de las ratas. In: El gaucho insufrible. Barcelona: Anagrama, 2003.

CHATWIN, Bruce. Colina negra. Trad. de Luciano Machado. São Paulo: Companhia das Letras, 2005. 1996. O rastro dos cantos. Trad. de Bernardo Carvalho. São Paulo: Companhia das Letras,

DAVENPORT, Guy. The Geography of Imagination. Boston: Nonpareil Books, 1997.

FERRARIS, Maurizio. Documentalità: perché è necessario lasciar tracce. Bari: Laterza, 2009.

GINZBURG, Carlo. Sinais: raízes de um paradigma indiciário. In: Mitos, emblemas e sinais: morfologia e história. Tradução de Federico Carotti. São Paulo: Companhia das Letras, 1990.

KAFKA, Franz. Josefina, a cantora ou O povo dos camundongos. In: Um artista da fome / A construção. Trad. de Modesto Carone. São Paulo: Companhia das Letras, 1998, p. 37-59.

KLEIN, Kelvin Falcão. O Atlas e as Passagens: rarefação do eu diante do arquivo, Revista Confluenze (Università di Bologna), v. 5, n. 1, p. 15-25, 2013.

Metamorfoses nas vanguardas: entre o homem e o animal. Viso: Cadernos de Estética Aplicada, Programa de Pós-Graduação em Estética da UFRJ, v. 9, p. 1-15, 2010.

Elogio da portabilidade, Revista Gragoatá (UFF - Niterói), v. 27, p. 135-154, 2009. 101, 2009a.

Enrique Vila-Matas em cinco imagens, Revista Poiésis (UFF - Niterói), v.14, p. 88-

NICHOLL, Charles. Traces remain: Essays and Explorations. Nova York: Penguin, 2011.

OLSEN, Kristin. Understanding Lord of the flies: a student casebook to issues, sources, and historical documents. Westport, Connecticut: Greenwood Press, 2000.

SHAKESPEARE, Nicholas. Bruce Chatwin. Londres: Vintage, 2000.

SHORTO, Russell. Descartes Bones: A Skeletal History of the Conflict between Faith and Reason. Nova York: Doubleday, 2008.

STALLYBRASS, Peter. O casaco de Marx: roupas, memória, dor. Trad. de Tomaz Tadeu. Belo Horizonte: Autêntica, 2008.

WILLIAMS, Pat; DENNEY, James. How to be like Walt: Capturing the Disney Magic Every Day of Your Life. Deerfield Beach, Flórida: Health Communications, 2004.

WRIGHT, John T. An Evacuee's Story: a North Yorkshire Family in Wartime. Harbury, Inglaterra: J. T. Wright, 2007. 
[Recebido e aceito para publicação em dezembro de 2013]

\section{Bruce Chatwin's Suitcase, Cipher of History}

Abstract: This essay seeks to investigate the critic impact of a childhood scene of the writer Bruce Chatwin, lived during the Second World War, from which arise two artifacts of main historical significance: the suitcase and the gas mask. The gas mask, however, have the peculiarity of being aimed at children and therefore have the shape and features of the Mickey Mouse character. Both the suitcase and the mask are read with the notion of "Dialectical Image", as developed by Walter Benjamin. The essay also draws on the reflections of the former author on the Mickey Mouse character, the reflection also expanding towards the ideas of Giorgio Agamben on miniaturization as a key to History, a phenomenon that is observed in the two artifacts selected for analysis in the text, the suitcase and the mask. The text indicates and aligns to what is configured as a new historiographical sensitivity in the human sciences, based on reading the traces left by the objects and their morphological peculiarities.

Keywords: Dialectical Image. World War II. Bruce Chatwin. Miniaturization. Memory.

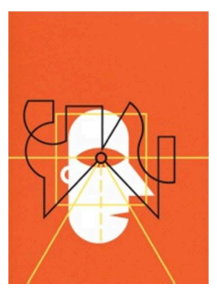

